\title{
Research Paper: Cortical Activity During Postural Recovery in Response to Predictable and Unpredictable Perturbations in Healthy Young and Older Adults: A Quantitative EEG Assessment
}

\author{
Zahra Saadat $^{1,2,3}$ (D), Ehsan Sinaei ${ }^{3,4}$ (D), Soraya Pirouzi ${ }^{2}$ (D), Mohsen Ghofrani ${ }^{4}$ (D), Mohammad Nami ${ }^{3,5,6,7^{*}}$ (C)
}

1. Student Research Committee, School of Rehabilitation Sciences, Shiraz University of Medical Sciences, Shiraz, Iran.

2. Department of Physical Therapy, School of Rehabilitation Sciences, Shiraz University of Medical Sciences, Shiraz, Iran.

3. Department of Neuroscience, Neuroscience Laboratory, School of Advanced Medical Sciences and Technologies, Shiraz University of Medical

Sciences, Shiraz, Iran.

4. Rehabilitation Sciences Research Center, Shiraz University of Medical Sciences, Shiraz, Iran.

5. Department of Neuroscience, School of Advanced Medical Sciences and Technologies, Shiraz University of Medical Sciences, Shiraz, Iran

6. DANA Brain Health Institute, Iranian Neuroscience Society, Fars Chapter, Shiraz, Iran.

7. Academy of Health, Senses Cultural Foundation, Sacramento, CA, USA.

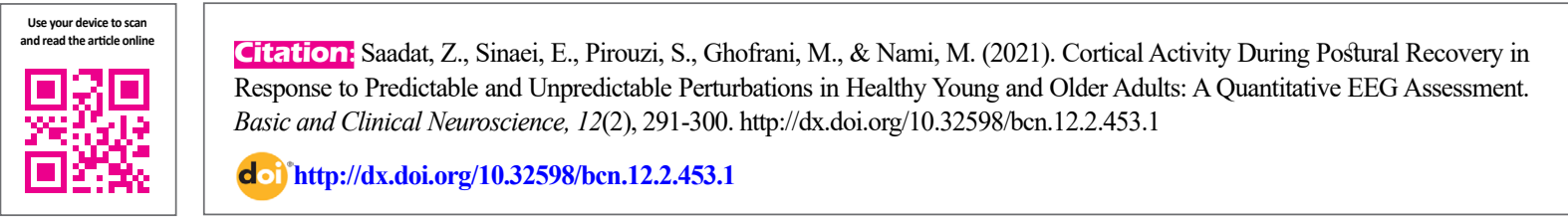

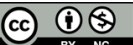

Article info:

Received: 17 Jun 2019

First Revision: 23 Jul 2019

Accepted: 16 Feb 2020

Available Online: 01 Mar 2021

Keywords:

Electroencephalography,

Brain waves, Postural balance,

Aging, Falling
A B S T RA C T

Introduction: To investigate the effects of predictable and unpredictable external perturbations on cortical activity in healthy young and older adults.

Methods: Twenty healthy older and 19 healthy young adults were exposed to predictable and unpredictable external perturbations, and their cortical activity upon postural recovery was measured using a 32-channel quantitative encephalography. The absolute spectral power and coherence z-scores of cortical waves were analyzed through a 3-way mixed ANOVA.

Results: During postural recovery from predictable perturbations, older adults exhibited higher frontoparietal beta power and higher alpha and beta coherence during the late-phase recovery than the young individuals. After unpredictable perturbations, the older group showed lower alpha power in the early phase and higher beta power in the late phase as compared to the young group. Results for the group $\times$ time and group $\times$ location interactions in the older group showed a higher alpha and beta coherence over the late phase, a higher alpha coherence in F3-P3 and F4-P4 regions, and a higher beta coherence in the F4-P4 region compared to the younger group.

Conclusion: Our results revealed that the cortical activation after external perturbations increases with aging, particularly in frontoparietal areas. A shift from automatic (subcortical level) to attentional (cortical level) processing may reflect the contribution of attentional resources for postural recovery from an external threat in older individuals.

\section{* Corresponding Author:}

Mohammad Nami, MD., PhD.

Address: Department of Neuroscience, Neuroscience Laboratory, School of Advanced Medical Sciences and Technologies, Shiraz University of Medical Sciences, Shiraz, Iran.

Tel: +98 (71) 32305471

E-mail: torabinami@sums.ac.ir 


\section{Highlights}

- In older adults, the cortical activation, particularly in frontoparietal areas, increases after external perturbations.

- Postural recovery in response to external perturbations requires attentional resources.

- Attentional demands associated with postural recovery may increase the risk of falling among older adults.

\section{Plain Language Summary}

Cortical activity in response to external perturbations was compared between 20 healthy older adults and 19 healthy young adults using encephalographic data. The absolute power and coherence of cortical waves were analyzed after predictable and unpredictable perturbations. Our results showed higher frontoparietal beta power in both predictable and unpredictable perturbations and lower alpha power in unpredictable perturbations in older participants. This finding suggests that when the balance task becomes more difficult, the cortical activity and attentional demands increase significantly. Our findings imply greater cortical activation during postural recovery following external perturbations with increasing age. Compelling evidence on this perspective would potentially pave the way towards adopting neurorehabilitation strategies.

\section{Introduction}

alling is a significant concern in older adults since it reduces mobility, causes dependence in daily activities, and even morbidity (Laessoe \& Voigt, 2008; Zwergal et al., 2012). Identifying potential underlying neural mechanisms of falls in older individuals may make it possible to design appropriate preventive and therapeutic interventions to alleviate inefficient postural recovery and reduce subsequent falls.

Postural recovery after external perturbations is necessary for older adults since many falls occur due to unexpected slips (Kanekar \& Aruin, 2014; Sobhani et al., 2018). The cerebral cortex plays an integral role in maintaining postural balance after both predictable and unpredictable perturbations (Bolton, 2015; Mochizuki, Sibley, Esposito, Camilleri, \& McIlroy, 2008; Quant, Adkin, Staines, \& McIlroy, 2004; Tse et al., 2013) by changing the central set during the early preparatory response phase, as well as modifying and optimizing the late response phase (Jacobs, 2014). According to the literature, the cerebello-cortical loop contributes to postural responses based on the individual's prior experiences, whereas the basal ganglio-cortical loop participates in the modification of postural responses with regard to body posture (Jacobs \& Horak, 2007; Smith, Jacobs, \& Horak, 2012).

It is well known that postural recovery declines progressively with aging, thereby increasing the risk of falls in older adults. A previous report has shown that the age-related deterioration of postural recovery is a multifactorial impairment resulting from decreased muscle strength, impaired peripheral nervous system function, decreased nerve conduction velocity, altered spinal reflexes, and functional and structural changes in the brain (Papegaaij, Taube, Baudry, Otten, \& Hortobagyi, 2014). The evidence suggested the delayed anticipatory postural adjustment and increased muscle coactivation following postural perturbations in healthy older adults compared to younger individuals (Kanekar \& Aruin, 2014). Moreover, greater involvement of particular brain regions, including the primary motor (M1), premotor, and prefrontal cortex, has been reported in older adults during motor tasks (Papegaaij et al., 2014).

A more in-depth understanding of cortical function associated with postural responses in older adults would potentially provide vital information to investigate the effects of neurorehabilitation balance training to improve postural control in this population. Accordingly, the present study was designed to investigate the role of cortical function in postural adjustment mechanisms after predictable and unpredictable perturbations in healthy older adults compared to healthy young individuals. Previous studies have indicated that sensorimotor cortices are predominantly involved in different aspects of motor control. The present report has strived to define the potential dynamics in cortical oscillatory power within the alpha and beta frequency bands and inter-hemispheric and intra-hemispheric changes in alpha and beta coherence upon postural control task in response to predictable and unpredictable perturbations. 


\section{Methods}

\subsection{Study participants}

In this comparative observational study, 19 healthy young adults (18-40 years old, 7 women and 12 men) and 20 healthy older individuals (60-75 years old, 9 women and $11 \mathrm{men}$ ) were recruited by a convenience sampling method through advertisements in the university premises and a retirement community, Shiraz City, Iran.

The inclusion criteria for older adults were obtaining scores of $\geq 24$ out of 30 in the Mini-Mental State Examination (MMSE) (Laessoe \& Voigt, 2008), <7 out of 15 in the Geriatric Depression Scale (GDS) (Yesavage et al., 1982), and $\geq 25$ out of 40 in the Fullerton advanced balance (FAB) scale to ensure appropriate balance ability (Rose, Lucchese, \& Wiersma, 2006), as well as the ability to stand and walk independently. Individuals in both groups were excluded if they had any history of neuromuscular or musculoskeletal disorders, uncorrected vision impairments, vestibular deficits, auditory dysfunctions or lower extremity pain, or if they were taking any medication potentially affecting their balance performance (Sinaei, Kmali, Nematollahi, \& Etminan, 2016). All participants signed an informed consent form, and ethical approval was obtained from the local medical Ethics Committee in accordance with the standards of the Declaration of Helsinki.

\subsection{Study procedure}

Postural perturbations were applied by releasing a load (mass $=3 \%$ of body weight) attached via a cable to a belt worn by participants at their sternum level. The participants stood barefoot with their feet $24 \mathrm{~cm}$ apart and were asked to maintain their postural balance after the load was released.

The experiment comprised blocks of 15 trials of predictable perturbations with eyes open, followed by blocks of 15 trials of unpredictable perturbations, in which participants wore blindfolds and earplugs to ensure the lack of any visual or auditory feedback. Perturbation blocks were presented in random order with 5-s to 15 -s rests between trials.

\subsection{Quantitative Electroencephalography (qEEG) measures}

The EEG signals were recorded with silver-chloride surface electrodes (Medico Electrodes International Ltd., Uttar Pradesh, India) mounted on an Electro Cap placed on participants' heads according to the international 10-20 system. A 32-channel NrSign 3840 EEG device (NrSign Inc., Vancouver, Canada) was used as an amplifier, and the FPz electrode was regarded as the reference point. The EEG data were collected at a sampling rate of $500 \mathrm{~Hz}$ with a $2-120 \mathrm{~Hz}$ bandpass filter, and the impedance was kept below $5 \mathrm{k} \Omega$ across channels.

\subsection{Data processing}

The EEG data were converted into ASCII format and imported into NeuroGuide Software (NG 2.5.5; Applied Neuroscience, St Petersburg, FL, USA). The recorded signals were preprocessed by an EEG expert and denoised to eliminate signals disturbed by eye movements or muscle artifacts. The difference with z-score absolute power was computed by fast Fourier transform based on the NeuroGuide qEEG normative database.

The exact moment of load release $(\mathrm{T} 0=0)$ was marked on the EEG tracing using a foot pedal triggered by the examiner. The T0 time point was considered the reference to which all EEG signals were compared and analyzed. Data were analyzed in three time intervals; the anticipatory postural adjustment (APA) from -1000 to $-500 \mathrm{~ms}$ (APA1), the APA from -500 to $0 \mathrm{~ms}$ (APA2), and the early compensatory postural adjustment (CPA) from 0 to $+500 \mathrm{~ms}$ (CPA1) (Mochizuki et al., 2008).

The acquired EEG signals upon each set of 15 trials were averaged, and the mean absolute power and coherence were calculated for alpha $(8-12 \mathrm{~Hz})$ and beta $(12.5-25 \mathrm{~Hz})$ frequency bands. The EEG derivations overlaying the right and left sensorimotor and primary motor areas were referred to as $\mathrm{C} 3$, and $\mathrm{C} 4$ and the power spectral analysis was performed in F3, F4, and P3, P4. Additionally, intra-hemispheric coherence for alpha and beta frequency bands was computed over dipoles, including F3-C3, F3-P3, C3-P3, F4-C4, F4-P4, and C4- P4. Meanwhile, inter-hemispheric coherence was computed for F3-F4, C3-C4, and P3-P4 electrode pairs (Meziane et al., 2015; Mochizuki et al., 2008; Tas et al., 2015).

The spectral power was scaled in microvolts $(\mu \mathrm{V})$, and calculations for respective changes in different states (for both power and coherence) were done based on the $\mathrm{z}$ score (Figure 1).

\subsection{Statistical analysis}

Data were analyzed with SPSS version 22.0 (IBM Corp., Armonk, NY, USA), and P value $<0.05$ was considered statistically significant. The normal distri- 


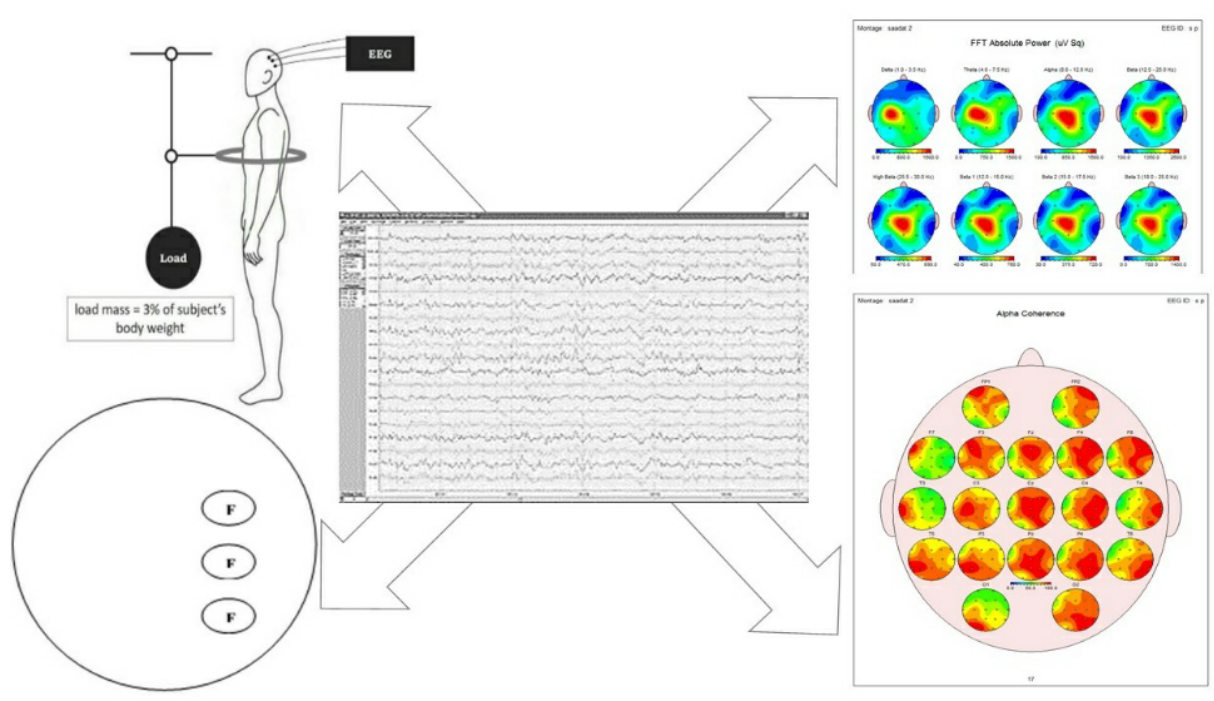

Figure 1. The schematic illustration of components of the experimental set-up used in the present trial

NEUR SCIENCE

bution of data was confirmed by the Shapiro-Wilk test $(\mathrm{P}>0.05)$. Absolute power was analyzed with a 3-way mixed ANOVA with one between-subject factor (older adults vs. young adults) and two within-subject factors, including the location (C3, P3, F3, C4, P4, and F4) and time (APA1, APA2, and CPA1) for each frequency band.

With regard to the coherence, a 3-way mixed ANOVA was used for each frequency band, with one betweensubject factor (the two groups) and two within-subject factors, including the location (C3-F3, C3-P3, F3-P3, C4-F4, C4-P4, F4-P4, C3-C4, F3-F4, and P3-P4) and time (APA1, APA2, and CPA1). Post hoc comparisons were made where applicable.

\section{Results}

\subsection{Study participants}

Forty-eight volunteers (28 older and 19 young individuals) were recruited between June and August 2017, 39 of whom met the eligibility criteria and participated in the study. The participants' demographic and baseline characteristics are summarized in Table 1.

\subsection{Predictable perturbations}

The results of 3-way ANOVAs for EEG absolute power and coherence during predictable perturbations summarized in Table 2 were as follows:
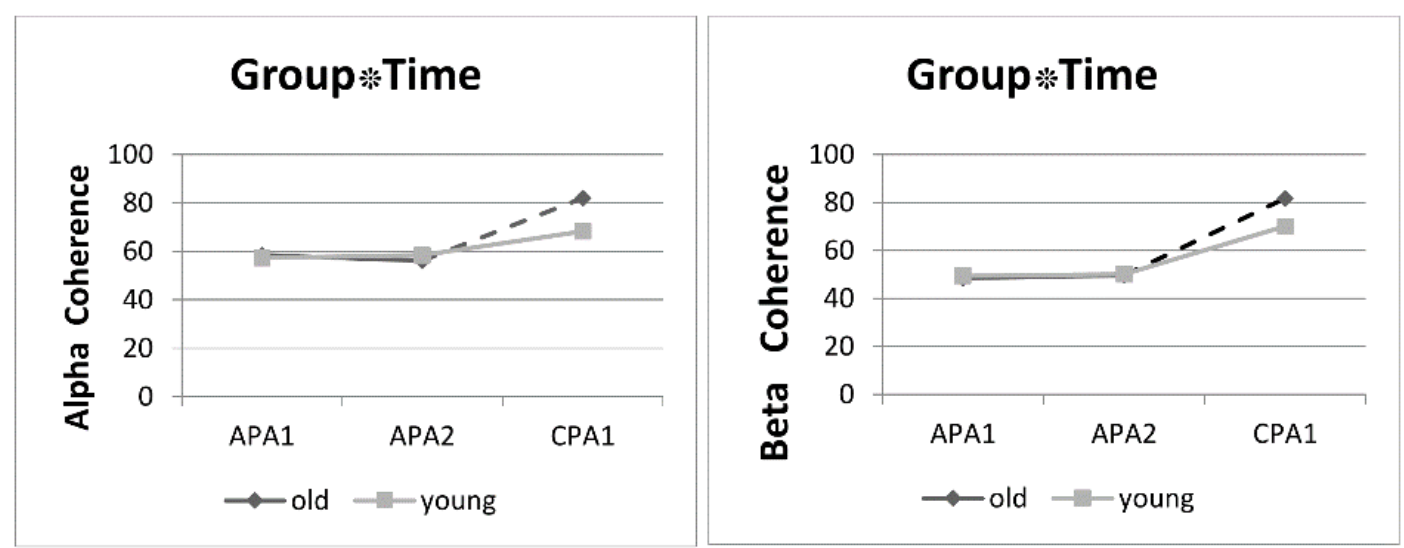

NEUR SCIENCE

Figure 2. The interaction effect of group (older and young adults) and time (APA1, APA2, and CPA1) for alpha and beta coherence after predictable perturbations 
Table 1. Demographic characteristics of the participants

\begin{tabular}{ccc}
\hline & \multicolumn{2}{c}{ No. (\%)/ Mean \pm SD } \\
\cline { 2 - 3 } Variable & Older Adults Group & Young Adults Group \\
\hline Female & $20(9)$ & $19(7)$ \\
\hline Age $(\mathrm{y})$ & $65.55 \pm 4.67$ & $24.25 \pm 3.15$ \\
\hline Weight $(\mathrm{kg})$ & $57.96 \pm 7.15$ & $55.77 \pm 7.88$ \\
\hline Height $(\mathrm{cm})$ & $163.00 \pm 4.86$ & $162.51 \pm 4.21$ \\
\hline MMSE (0-30) & $27.79 \pm 1.81$ & NA \\
\hline GDS (0-15) & $1.84 \pm 1.53$ & NA \\
\hline FAB (0-40) & $35.58 \pm 2.75$ & NA \\
\hline
\end{tabular}

NEUR SCIENCE

SD: Standard Deviation; MMSE: Mini-Mental State Examination; GDS: Geriatric Depression Scale; FAB: Fullerton Advanced Balance Scale; NA: Not applicable.

1. Power spectral density: The main group effect was significant for beta power, indicating higher beta power in the older than the young adults' group.

2. The z-score coherence: The group $\times$ time interaction was significant, and the older group had significantly higher alpha and beta coherence in CPA1 than the young adults' group (Figure 2). The location $\times$ time interaction was also significant for both frequency bands. Post hoc analyses showed that coherence was significantly different between APA1-CPA1 and APA2-CPA1 phases across the regions of interest for beta coherence and between APA1-CPA1 and APA2-CPA1 phases in F3-P3, $\mathrm{F} 4-\mathrm{P} 4, \mathrm{C} 3-\mathrm{C} 4$, and $\mathrm{F} 3-\mathrm{F} 4$ regions for alpha coherence.
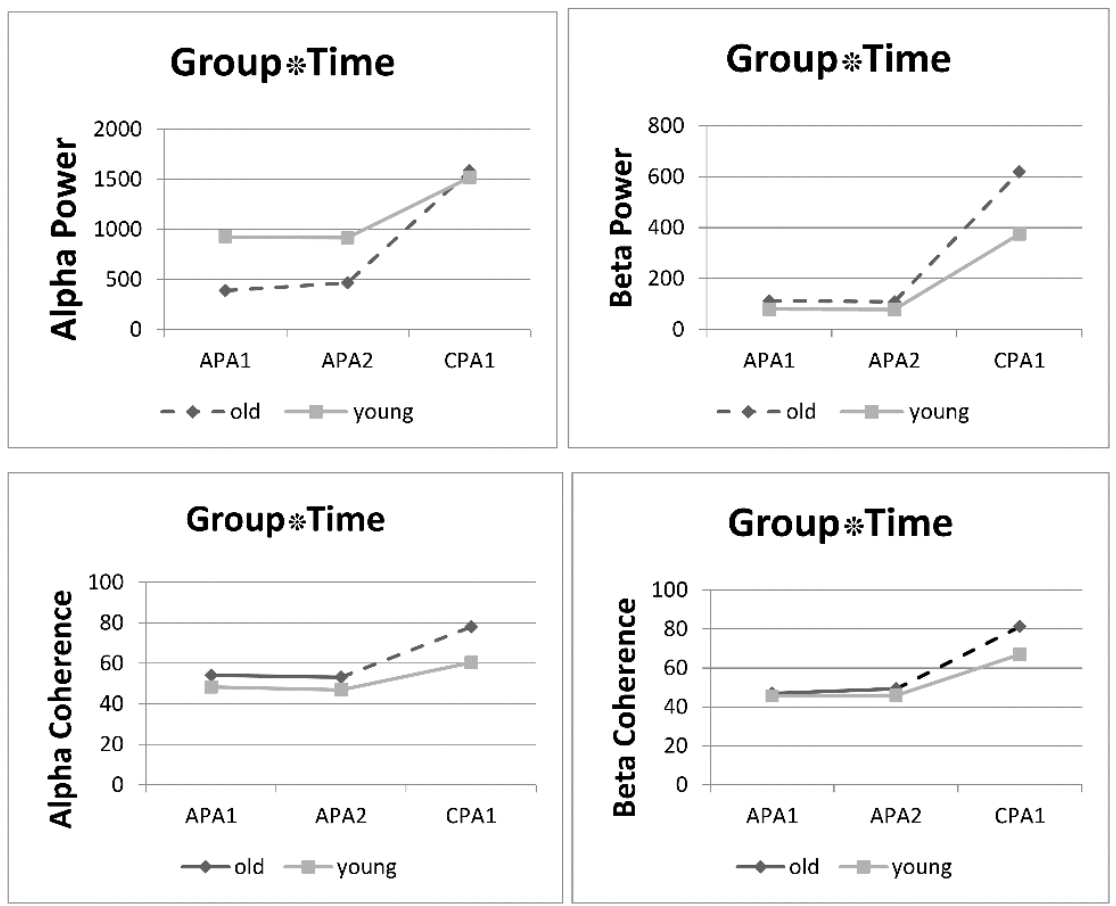

NEUR SCIENCE

Figure 3. The interaction effect of group (old and young) and time (APA1, APA2, and CPA1) for power and coherence of both frequency bands after unpredictable perturbations 
Table 3. EEG absolute power and coherence values after unpredictable perturbations

\begin{tabular}{|c|c|c|c|c|c|}
\hline \multirow{2}{*}{ Frequency Band } & \multirow{2}{*}{$\begin{array}{c}\text { Variables } \\
\text { and Interactions }\end{array}$} & \multicolumn{2}{|c|}{ Power } & \multicolumn{2}{|c|}{ Coherence } \\
\hline & & F Ratio & $\mathbf{P}$ & F Ratio & $\mathbf{P}$ \\
\hline \multirow{7}{*}{$\begin{array}{c}\text { Alpha } \\
(8-12 \mathrm{~Hz})\end{array}$} & Group & 10.84 & $0.001^{*}$ & 66.44 & $<0.001^{*}$ \\
\hline & Time & 39.34 & $<0.001^{*}$ & 105.50 & $<0.001^{*}$ \\
\hline & Location & 33.35 & $<0.001^{*}$ & 44.78 & $<0.001^{*}$ \\
\hline & Group $\times$ Time & 4.07 & $0.01 *$ & 10.13 & $<0.001^{*}$ \\
\hline & Group $\times$ Location & 6.46 & $<0.001^{*}$ & 4.71 & $<0.001^{*}$ \\
\hline & Location $\times$ Time & 0.08 & 1.00 & 4.13 & $<0.001^{*}$ \\
\hline & Group $\times$ Time $\times$ Location & 0.26 & 0.98 & 0.33 & 0.99 \\
\hline \multirow{7}{*}{$\begin{array}{c}\text { Beta } \\
(12.5-25 \mathrm{~Hz})\end{array}$} & Group & 15.81 & $<0.001^{*}$ & 30.95 & $<0.001^{*}$ \\
\hline & Time & 107.93 & $<0.001^{*}$ & 255.48 & $<0.001^{*}$ \\
\hline & Location & 2.59 & $0.02 *$ & 35.55 & $<0.001^{*}$ \\
\hline & Group $\times$ Time & 7.62 & $0.001^{*}$ & 12.67 & $<0.001^{*}$ \\
\hline & Group $\times$ Location & 0.48 & 0.78 & 3.90 & $<0.001^{*}$ \\
\hline & Location $\times$ Time & 0.14 & 0.99 & 2.29 & $0.003^{*}$ \\
\hline & Group $\times$ Time $\times$ Location & 0.50 & 0.88 & 0.21 & 1.00 \\
\hline
\end{tabular}

*Asterisks indicate statistically significant values $(\mathrm{P}<0.05)$.

NEUR SCIENCE

In other words, alpha and beta coherence were higher in the late phase in both groups.

\subsection{Unpredictable perturbations}

Table 3 outlines the results of 3-way ANOVAs for EEG absolute power and coherence values during unpredictable perturbations, as follows:

1. Power spectral density: The group $\times$ location interaction was significant for alpha power, with the young individuals group showing a higher alpha power in the $\mathrm{P} 4$ region than the older group. The group $\times$ time interaction was also significant for both alpha and beta bands, and the post hoc analyses indicated a significantly lower alpha power in the early phases (APA1 and APA2) and higher beta power in the late phase (CPA1) in the older adults group.

2. The z-score coherence: The group $\times$ time, group $\times$ location, and location $\times$ time interactions were significant for both frequency bands. Post hoc analyses of the group $\times$ time interactions showed that the older group had a significantly greater alpha and beta z-score coher- ence in CPA1 than the young adults' group (Figure 3). Post hoc analyses of the group $\times$ location interaction for alpha and beta coherence showed significantly higher alpha coherence in the F3-P3 and F4-P4 regions and higher beta coherence in the F4-P4 region in the older group compared to the young adults' group.

In addition, the beta coherence was significantly different between the APA1-CPA1 and APA2-CPA1 phases in all regions, and the alpha coherence differed significantly between the APA1-CPA1 and APA2-CPA1 phases in F3-P3, F4-P4, C3-C4, and F3-F4 regions. Our findings revealed the highest values for alpha and beta coherence in the late phase in both groups.

\section{Discussion}

Our results demonstrated higher frontoparietal beta power after both predictable and unpredictable perturbations and lower alpha power following unpredictable perturbations in older adults. Motor control is achieved by integrating and coordinating sensorimotor processing through the activation of various cerebral cortical regions during functional tasks (Chang, Yang, Yang, \& Chern, 
Table 2. EEG absolute power and coherence values after predictable perturbations

\begin{tabular}{|c|c|c|c|c|c|}
\hline \multirow{2}{*}{ Frequency Band } & \multirow{2}{*}{$\begin{array}{c}\text { Variables } \\
\text { and Interactions }\end{array}$} & \multicolumn{2}{|c|}{ Power } & \multicolumn{2}{|c|}{ Coherence } \\
\hline & & F Ratio & $\mathbf{P}$ & F Ratio & $\mathbf{P}$ \\
\hline \multirow{7}{*}{$\begin{array}{c}\text { Alpha } \\
(8-12 \mathrm{~Hz})\end{array}$} & Group & 0.005 & 0.94 & 10.19 & $0.001 *$ \\
\hline & Time & 126.46 & $<0.001^{*}$ & 80.39 & $<0.001^{*}$ \\
\hline & Location & 3.04 & $0.01^{*}$ & 24.75 & $<0.001^{*}$ \\
\hline & Group $\times$ Time & 1.46 & 0.23 & 14.04 & $<0.001^{*}$ \\
\hline & Group $\times$ Location & 0.34 & 0.88 & 1.31 & 0.23 \\
\hline & Location $\times$ Time & 0.06 & 1.00 & 2.56 & $0.001 *$ \\
\hline & Group $\times$ Time $\times$ Location & 0.36 & 0.96 & 0.42 & 0.97 \\
\hline \multirow{7}{*}{$\begin{array}{c}\text { Beta } \\
(12.5-25 \mathrm{~Hz})\end{array}$} & Group & 3.92 & $0.04 *$ & 8.51 & $0.004^{*}$ \\
\hline & Time & 138.89 & $<0.001^{*}$ & 230.52 & $<0.001^{*}$ \\
\hline & Location & 1.01 & 0.40 & 32.89 & $<0.001^{*}$ \\
\hline & Group $\times$ Time & 0.88 & 0.41 & 12.49 & $<0.001^{*}$ \\
\hline & Group $\times$ Location & 0.43 & 0.82 & 1.58 & 0.12 \\
\hline & Location $\times$ Time & 0.09 & 1.00 & 2.17 & $0.005^{*}$ \\
\hline & Group $\times$ Time $\times$ Location & 0.35 & 0.96 & 0.28 & 0.99 \\
\hline
\end{tabular}

*Asterisks indicate statistically significant values ( $\mathrm{P}$-value $<0.05)$.

NEUR:SCIENCE

2016). It has been postulated that the aging process, which is accompanied by reduced conduction velocity and degeneration of somatosensory receptors (Papegaaij et al., 2014; Zwergal et al., 2012), may lead to postural control deficits, increasing the risk of falls. Therefore, the compensatory strategies to regain postural stability after balance perturbations are essential to prevent falls.

Evidence supports that the cerebral cortex plays a crucial role in controlling compensatory reactions and modifying postural responses through cortical response loops (Jacobs \& Horak, 2007; Sipp, Gwin, Makeig, and Ferris, 2013; Slobounov, Cao, Jaiswal, \& Newell, 2009; Slobounov, Hallett, Stanhope, \& Shibasaki, 2005). For instance, the prefrontal cortex is activated after external perturbations with or without auditory warning (Mihara, Miyai, Hatakenaka, Kubota, \& Sakoda, 2008). Compared to young adults, older adults seem to activate more brain areas to maintain postural stability in different conditions, particularly in the prefrontal cortex and the basal ganglia (Seidler et al., 2010). The activation of such brain regions in older adults may reflect a greater reliance on cognitive processing to compensate for sensorimotor impairments (Papegaaij et al., 2014; Seidler et al., 2010). An earlier report suggested that beta bands are more related to cognitive aspects of motor control (i.e. higher cortical activity), whereas the alpha band is more involved in automatic movement processing (Klimesch 1999). Automaticity of motor behavior is defined as being "less dependent on cognitive processes" and is associated with greater subcortical activation rather than the cortical or conscious mental activity (Moors \& De Houwer, 2006). Motor tasks with less difficulty and welllearned balance strategies that do not need significant cortical activation may be processed subcortically (Tas et al., 2015). Teasdale et al. have reported that greater cognitive processing is required during more challenging postural tasks (Teasdale \& Simoneau, 2001). As such, the increased beta power following both predictable and unpredictable perturbations may reflect the higher cortical activity required for more demanding tasks (Slobounov et al., 2005; Tas et al., 2015).

On the other hand, a shift from the alpha to the beta band during unpredictable perturbations (i.e. lower-alpha power to higher beta power) indicates that these conditions are more difficult and attention-demanding in older adults, necessitating greater cortical activity. When the 
balance task becomes more demanding (e.g., because of reduced vision or support surface perturbations), cortical activity may significantly increase (Tas et al., 2015). Our finding was in line with several studies which reported a power gain in frequencies below $7 \mathrm{~Hz}$ and the opposite in frequencies over $7 \mathrm{~Hz}$ (Tas et al., 2015).

Additionally, that alpha and beta z-score coherence values increased after both predictable and unpredictable perturbations in the present study. According to the literature, the coherence can be interpreted as a reflection of functional and structural connectivity (Burroughs, Morse, Mott, \& Holmes, 2014), and increased coherence may be attributed to enhanced connectivity between cerebral structures or cortical-subcortical circuitry resulting in the synchronization of cortical activities (Burroughs et al., 2014). Furthermore, the increased cortical activity seems necessary for older adults to perform walking and balance tasks, while activation patterns may vary with the demands of the particular task. Taken together, studies have attributed cortical activation to compensatory mechanisms for underlying age-related deficits in automatic movement control (Stuart et al., 2018).

In the present study, however, we recruited only healthy individuals, and hence, the results may not be generalizable to other populations, including older adults with cognitive disorders or balance impairments. Moreover, it is suggested to examine other forms of perturbations such as external perturbations in medial-lateral or vertical directions and postural control over unstable bases of support.

In conclusion, an age-associated shift in postural control from an automatic, subcortical level to an attentional, cortical level may reflect the role of cognitive processes in postural recovery after external perturbations in older adults. Our results provide preliminary evidence that cortical activations following external perturbations tend to increase with age, and this compensatory strategy can contribute to postural recovery in individuals with agerelated sensorimotor deficits. Compelling evidence on this perspective would potentially pave the way towards strategizing neurorehabilitation strategies using state-ofthe-art neurotechnologies.

\section{Ethical Considerations}

\section{Compliance with ethical guidelines}

This study was approved by the Ethics Committee of the Shiraz University of Medical Sciences (Code: IR.SUMS.REC.1396.26).

\section{Funding}

This study was supported by the Shiraz University of Medical Sciences, Shiraz City, Iran.

\section{Authors' contributions}

Conceptualization and methodology: Zahra Saadat, Ehsan Sinaei, Soraya Piroozi, and Mohammad Nami; Formal analysis: Zahra Saadat, Mohsen Ghofrani, and Mohammad Nami; Investigation and data curation: Zahra Saadat and Ehsan Sinaei; Writing the original draft preparation, review, and editing: Zahra Saadat, Ehsan Sinaei, and Mohammad Nami; Supervision and funding acquisition: Soraya Piroozi, and Mohammad Nami.

\section{Conflict of interest}

The authors had no conflict of interest to declare.

\section{Acknowledgments}

The authors would like to thank the manager of the Jahandidegan Daily Center (Mrs. Roya Razavi) and all volunteers who participated in this study.

\section{References}

Bolton, D. A. (2015). The role of the cerebral cortex in postural responses to externally induced perturbations. Neuroscience \& Biobehavioral Reviews, 57, 142-55. [DOI:10.1016/j.neubiorev.2015.08.014] [PMID]

Burroughs, S. A., Morse, R. P., Mott, S. H., \& Holmes, G. L. (2014). Brain connectivity in West syndrome. Seizure, 23(7) 576-9. [DOI:10.1016/j.seizure.2014.03.016] [PMID] [PMCID]

Chang, C. J., Yang, T. F., Yang, S. W., \& Chern, J. S. (2016). Cortical modulation of motor control biofeedback among the elderly with high fall risk during a posture perturbation task with augmented reality. Frontiers in Aging Neuroscience, 8, 80. [DOI:10.3389/fnagi.2016.00080]

Jacobs, J. V. (2014). Why we need to better understand the cortical neurophysiology of impaired postural responses with age, disease, or injury. Frontiers in integrative neuroscience, 8, 69 . [DOI:10.3389/fnint.2014.00069] [PMID] [PMCID]

Jacobs, J. V., \& Horak, F. B. (2007). Cortical control of postural responses. Journal of Neural Transmission, 114(10), 1339-48, [DOI:10.1007/s00702-007-0657-0] [PMID] [PMCID]

Kanekar, N., \& Aruin, A. S. (2014). The effect of aging on anticipatory postural control. Experimental Brain Research, 232(4), 112736. [DOI:10.1007/s00221-014-3822-3] [PMID] [PMCID]

Klimesch, W. (1999). EEG alpha and theta oscillations reflect cognitive and memory performance: A review and analysis. Brain 
Research Reviews, 29(2-3), 169-95. https://www.sciencedirect. com/science/article/abs/pii/S0165017398000563

Laessoe, U., \& Voigt, M. (2008). Anticipatory postural control strategies related to predictive perturbations. Gait \& Posture, 28(1), 62-8. [DOI:10.1016/j.gaitpost.2007.10.001] [PMID]

Meziane, H. B., Moisello, C., Perfetti, B., Kvint, S., Isaias, I. U., \& Quartarone, A., et al. (2015). Movement preparation and bilateral modulation of beta activity in aging and Parkinson's disease. PloS One, 10(1), e0114817. [DOI:10.1371/journal. pone.0114817] [PMID] [PMCID]

Mihara, M., Miyai, I., Hatakenaka, M., Kubota, K., \& Sakoda, S. (2008). Role of the prefrontal cortex in human balance control. Neuroimage, 43(2), 329-36. [DOI:10.1016/j.neuroimage.2008.07.029] [PMID]

Mochizuki, G., Sibley, K. M., Esposito, J. G., Camilleri, J. M., \& Mcllroy, W. E. (2008). Cortical responses associated with the preparation and reaction to full-body perturbations to upright stability. Clinical Neurophysiology, 119(7), 1626-37. [DOI:10.1016/j.clinph.2008.03.020] [PMID]

Moors, A., \& De Houwer, J. (2006). Automaticity: A theoretical and conceptual analysis. Psychological Bulletin, 132(2), 297-326. [DOI:10.1037/0033-2909.132.2.297] [PMID]

Papegaaij, S., Taube, W., Baudry, S., Otten, E., \& Hortobagyi, T. (2014). Aging causes a reorganization of cortical and spinal control of posture. Frontiers in Aging Neuroscience, 6, 28. [DOI:10.3389/fnagi.2014.00028]

Quant, S., Adkin, A. L., Staines, W. R., \& McIlroy, W. E. (2004). Cortical activation following a balance disturbance. Experimental Brain Research, 155(3), 393-400. [DOI:10.1007/s00221-0031744-6] [PMID]

Rose, D. J., Lucchese, N., \& Wiersma, L. D. (2006). Development of a multidimensional balance scale for use with functionally independent older adults. Archives of Physical Medicine and Rehabilitation, 87(11), 1478-85. [DOI:10.1016/j.apmr.2006.07.263] [PMID]

Seidler, R. D., Bernard, J. A., Burutolu, T. B., Fling, B. W., Gordon, M. T., \& Gwin, J. T., et al. (2010). Motor control and aging: links to age-related brain structural, functional, and biochemical effects. Neuroscience \& Biobehavioral Reviews, 34(5), 721-33. [DOI:10.1016/j.neubiorev.2009.10.005] [PMID] [PMCID]

Sinaei, E., Kamali, F., Nematollahi, A., \& Etminan, Z. (2016). Comparing the effects of balance training with and without cognitive tasks on the quality of life and balance performance in community-dwelling older adults: A single-blind randomized clinical trial. Journal of Rehabilitation Sciences \& Research, 3(4), 91 6. [DOI:10.30476/JRSR.2016.41106]

Sipp, A. R., Gwin, J. T., Makeig, S., \& Ferris, D. P. (2013). Loss of balance during balance beam walking elicits a multifocal theta band electrocortical response. Journal of Neurophysiology, 110(9), 2050-60. [DOI:10.1152/jn.00744.2012] [PMID] [PMCID]

Slobounov, S., Cao, C., Jaiswal, N., \& Newell, K. M. (2009). Neural basis of postural instability identified by VTC and EEG. Experimental Brain Research, 199(1), 1-16. [DOI:10.1007/ s00221-009-1956-5] [PMID] [PMCID]

Slobounov, S., Hallett, M., Stanhope, S., \& Shibasaki, H. (2005). Role of cerebral cortex in human postural control: An EEG study. Clinical Neurophysiology, 116(2), 315-23. [DOI:10.1016/j. clinph.2004.09.007] [PMID]
Smith, B. A., Jacobs, J. V., \& Horak, F. B. (2012). Effects of magnitude and magnitude predictability of postural perturbations on preparatory cortical activity in older adults with and without Parkinson's disease. Experimental Brain Research, 222(4), 455-70. [DOI:10.1007/s00221-012-3232-3] [PMID] [PMCID]

Sobhani, S., Sinaei, E., Motealleh, A., Hooshyar, F., SamiKashkooli, N., \& Kordi-Yoosefinejad, A. (2018). Combined effects of whole body vibration and unstable shoes on balance measures in older adults: A randomized clinical trial Archives of Gerontology and Geriatrics, 78, 30-7. [DOI:10.1016/j. archger.2018.05.016].

Stuart, S., Vitorio, R., Morris, R., Martini, D. N., Fino, P. C., \& Mancini, M. (2018). Cortical activity during walking and balance tasks in older adults and in people with Parkinson's disease: A structured review. Maturitas, 113, 53-72. [DOI:10.1016/j.maturitas.2018.04.011] [PMID] [PMCID]

Tas, C., Cebi, M., Tan, O., Hizli-Sayar, G., Tarhan, N., \& Brown, E. C. (2015). EEG power, cordance and coherence differences between unipolar and bipolar depression. Journal of Affective Disorders, 172, 184-90. [DOI:10.1016/j.jad.2014.10.001] [PMID]

Teasdale, N., \& Simoneau, M. (2001). Attentional demands for postural control: The effects of aging and sensory reintegration. Gait \& Posture, 14(3), 203-10. [DOI:10.1016/S09666362(01)00134-5]

Tse, Y. Y., Petrofsky, J. S., Berk, L., Daher, N., Lohman, E., \& Laymon, M. S., et al. (2013). Postural sway and rhythmic electroencephalography analysis of cortical activation during eight balance training tasks. Medical Science Monitor, 19, 175-86. [DOI:10.12659/MSM.883824] [PMID] [PMCID]

Yesavage, J. A., Brink, T. L., Rose, T. L., Lum, O., Huang, V., \& Adey, M., et al. (1982). Development and validation of a geriatric depression screening scale: A preliminary report. Journal of Psychiatric Research, 17(1), 37-49. [DOI:10.1016/00223956(82)90033-4]

Zwergal, A., Linn, J., Xiong, G., Brandt, T., Strupp, M., \& Jahn, K. (2012). Aging of human supraspinal locomotor and postural control in fMRI. Neurobiology of Aging, 33(6), 1073-84. [DOI:10.1016/j.neurobiolaging.2010.09.022] [PMID] 
This Page Intentionally Left Blank 